\title{
Tonlk PERANCANGAN BUKU ILUSTRASI CERITA RAKYAT SUKU MALIND
}

Volume 1, Nomor 1

Juli 2019,

(69-74)

\section{Lejar Daniartana Hukubun}

Pascasarjana ISI Yogyakarta

e-mail : Lejarhukubun@gmail.com

\begin{abstract}
ABSTRAK
Merauke merupakan tempat yang istimewa, karena berada di ujung timur pulau Indonesia. Di kota tersebut dikaruniai berbagai macam kekayaan alam dan budaya setempat. Salah satu budaya asli dari daerah tersebut adalah suku Malind, yang memberikan keunikan dan kekhas an kota Merauke. Namun belum banyak yang mendokumentasinya secara terltulis. Tujuan yang dingin dicapai adalah merancang buku ilustrasi buku cerita rakyat suku Malind dalam bentuk karakter Wayang Papua, dengan begitu memberikan kebaruan dalam menyampaikan sebuah pesan, serta melestarian cerita rakyat suku Malind. Metode yang digunakan dalam perancangan ini menggunakan analisis $5 \mathrm{~W} 1 \mathrm{H}$ dan design thinking. Metode yang bervariasi bertujuan untuk mendapatkan data secara valid. Pengumpulan data dilakukan dengan cara observasi, wawancara, dan dokumentasi. Teori yang digunakan adalah teori Desain Komunikasi Visual. Manfaat yang dapat diperoleh dari teori adalah untuk mendapatkan jawaban dari masalah melalui strategi, pengamatan, referensi serta pengalaman yang mereka alami. Perancangan ini ditujukan untuk anak-anak usia 7 hingga 12 tahun. Perancangan ini menerapkan konsep komunikasi dan ungkapan daya kreatif agar dapat diterima oleh target audience. Selain itu, target audience diharapkan dapat memecahkan masalah melalui pesan visual. Perancangan buku ilustrasi cerita rakyat suku Malind merupakan solusi, agar salah satu kebudayaan Malind berupa cerita rakyat dapat dilestarikan. Misinya agar anak-anak sejak dini mulai mengenal kebudayaan mereka, dengan begitu kebudayaan ini dapat dilestarikan.
\end{abstract}

Kata kunci: buku ilustrasi, cerita rakyat malind, wayang Papua

\section{ABSTRACT}

Merauke is a special place, because it is on the eastern tip of the island of Indonesia. In the city it is blessed with various kinds of natural resources and local culture. One of the indigenous cultures of the area is the Malind tribe, which gives uniqueness and distinctiveness to the city of Merauke. But not many have documented it in writing. The cool goal is to design a book of illustrations of Malind folklore books in the form of Papuan puppet characters, thus giving newness in delivering a message, as well as preserving Malind tribal folklore. The method used in this design uses $5 \mathrm{~W} 1 \mathrm{H}$ analysis and design thinking. Varied methods aim to obtain data validly. Data collection is done by observation, interviews, and documentation. The theory used is the theory of Visual Communication Design. The benefits that can be obtained from theory are to get answers to problems through strategies, observations, references and experiences they experience. This design is intended for children aged 7 to 12 years. This design applies the concept of communication and expression of creative power so that it can be accepted by the target audience. In addition, the target audience is expected to solve problems through visual messages. The design of an illustrated Malind folklore book is a solution, so that one of the Malind cultures in the form of folk tales can be preserved. Its mission is that children start to recognize their culture early, so that this culture can be preserved.

Keywords: illustration book, malind folktale, wayang Papua

\section{PENDAHULUAN}

Indonesia memiliki keberagaman agama, suku, keindahan alam dan budayanya yang tersebar dari Sabang sampai Merauke. Hal ini menjadi kebanggan kita sebagai warga negara Republik Indonesia. Sebagai warga negara yang cinta akan kekayaan bangsanya, wajib bagi kita untuk menjaga dan memelihara keanekaragaman budaya bangsa Indonesia. Cerita rakyat merupakan salah satu warisan budaya yang penting untuk diajarkan.
Sebagai bagian dari hasil budaya, cerita rakyat suku Malind menjadi alat untuk mengenalkan kearifan lokal daerah setempat, termasuk penerapan nilainilai sosial budaya yang berlaku di masyarakat. Manfaat cerita rakyat antara lain menyampaikan pesan moral bagi pembaca, terutama bagi anakanak, agar memiliki budi pekerti yang baik dan dapat mengenal budaya lokal yang memiliki keunikan masing-masing daerah. Salah satu kebiasaan yang wajib ditanamkan kepada anakanak adalah membaca. Sehingga diperlukan bahan 
bacaan yang berkualitas dan bermanfaat. Buku cerita rakyat menjadi salah satu pilihan bacaan yang bermanfaat, karena cerita rakyat mengandung norma-norma yang mempengaruhi perkembangan moral anak, melatih kecerdasan anak secara visual, emosional, kognitif/pengetahuan, dan spiritual.

Cerita rakyat suku Malind, merupakan salah satu budaya lokal Indonesia, sehingga perlu kita cintai dan pelihara dengan baik. Perancangan ini menunjang pelestarian kebudayan lokal, sehingga untuk menjadi desainer grafis Indonesia, diperlukan solusi untuk menunjang tujuan tersebut. Salah satunya seperti yang pernah dinyatakan oleh Sumbo Tinarbuko (dalam Concept, 2015:25) bahwa untuk menjadi desainer grafis yang mengedepankan prinsip kelokalan dibutuhkan cara dengan melihat sebayak $25 \%$, mengamati 25\%, mempelajari $25 \%$ dan $25 \%$ mencintai dan bersahabat dengan budaya lokal Indonesia.

Untuk mewujudkan hal ini diperlukan media dalam menyampaikan sebuah pesan. Media tersebut yaitu sebuah buku. Berdasarkan bentuknya, terdapat dua jenis buku yaitu buku cetak dan buku digital. Pada dasarnya keduanya mempunyai kelebihan dan kekurangannya masingmasing dalam memerankan fungsinya sebagai media. Media digital mempunyai sifat praktis dalam kondisi tertentu, misalnya memudahkan untuk dibawa dalam perjalanan ke suatu tempat. Sedangkan kekurangannya yaitu dibutuhkan listrik dan bantuan media digital lainnya seperti laptop, sambungan internet, handphone. Menurut (Olsen, 1994) saat seseorang membaca buku cetak pembaca memindai bacaan untuk menemukan informasi tertentu, sekaligus mengingat informasinya dengan menandai letaknya dalam buku. Ingatan visual ini tidak terjadi pada kegiatan menelusuri bacaan digital (scrolling up, scrolling down). Teks digital umumnya dibaca secara parsial, sehingga pembaca tidak membacanya sebagai satu kesatuan ide secara utuh.

Konten digital lebih digemari karena menawarkan jalan pintas untuk mengakses informasi, dan keunggulan multimodalitasnya. Teks, gambar, atau elemen visual lainnya, suara, dan fitur interaktif sebagai unsur-unsur yang melengkapi teks digital. Paket ini lengkap untuk mengakomodasi bagi pembaca berkebutuhan khusus atau pembaca dengan gaya belajar visual, auditori, dan kinestetik. Sehingga kebutuhan kedua media cetak maupun digital saling melengkapi. Media digital lebih sesuai untuk kebutuhan instan, sedangkan media cetak membantu memahami informasi secara menyeluruh (Dewayani, 2017:36).

Buku dalam perancangan ini dibuat dengan menggunakan media cetak, karena media ini dapat memberikan durasi waktu yang panjang, dari pada media digital. Menggunakan media digital, salah satunya dapat bermanfaat untuk menyimpan data lewat format JPEG, untuk beberapa tahun ke depan apakah format tersebut masih bisa bertahan dan apakah gambar tersebut bisa dibuka tanpa ada gangguan?

Sehingga dapat dikatakan media cetak salah satunya buku, menjadi salah satu solusi sebagai media yang memiliki sifat tak lengkang oleh waktu.

Manfaat lain dari media cetak adalah perancangan yang menekankan pada perihal arsip dan waktu, diwujudkan melalui ilustrasi buku. Walapun perkembangan jaman dan teknologi semakin maju dalam menyampaikan pesan komunikasi visual, namun buku cetak menjadi salah satu solusi yang masih relevan hingga saat ini.

Cerita rakyat yang diangkat dalam perancangan buku ilustrasi ini adalah cerita rakyat suku Malind. Menurut Samkakai (2013), sebelum terjadi pemekaran kabupaten, suku Malind \& Suku Asmat berada dalam satu daerah atau satu kabupaten Merauke. Setelah pemekaran suku Malind tetap berada di kabupaten Merauke, dan Suku Asmat membentuk kabupaten yang baru yaitu kabupaten Asmat. Keduanya berada dalam satu propinsi yaitu propinsi Papua. Makanan pokok masyarakat Malind adalah sagu. Suku ini lebih banyak memiliki sistem mata pencaharian hidup dengan cara tradisional terutama dalam cara berburu dan menangkap ikan. Penangkapan ikan dilakukan dengan cara menjaring, menombak, dan memanah. Sedangkan pekerjaan masyarakat Malind yang lain adalah pegawai negeri, TNI, wiraswasta, dan petani.

Berdasarkan informasi dari tokoh-tokoh masyarakat Papua yang berdomisili di Yogyakarta, cerita rakyat suku Malind ini masih masuk dalam budaya lisan dan belum ada yang mendokumentasikan dalam bentuk buku atau media lainnya, sehingga penyebarannya menjadi sangat terbatas. Dijelaskan pula bahwa hasil budaya lokal ini hampir punah karena diterjang oleh budaya lainnya ataupun cerita-cerita dari luar etnis ini. Sedangkan penggalian data melalui searching google dengan kata kunci cerita rakyat suku Malind, hanya terdapat dari kurang dari 15 artikel yang terkait dengan objek, dan dari segi isi materi lebih banyak masih bersifat umum. Sehingga diperlukan proses sosialisasi melalui media, dalam hal ini berupa buku, karena cerita rakyat suku Malind sebagai salah satu aset budaya yang memiliki nilai keunikan budaya.

Fakta menunjukkan bahwa cerita rakyat yang ada sudah menjadi legenda, mitos, fabel ataupun sejenisnya, tetapi hal itu sifatnya masih menjadi budaya lisan yang penyampaiannya harus diceriterakan oleh orang tua pada anak-anak. Sementara yang terjadi sampai saat ini, banyak anak-anak yang lebih menyukai cerita-cerita yang disampaikan melalui media iklan, televisi dan perangkat atau alat-alat kecerdasan buatan, seperti 
handphone atau bentuk gadget lainnya, dengan demikian pesan yang akan disampaikan cepat hilang, sehingga diperlukan buku sebagai media untuk mewadahi cerita rakyat agar dapat memiliki fungsi sepanjang waktu. Hal ini menjadi kebutuhan masyarakat. Untuk itu, sebuah buku cerita rakyat dimunculkan agar dapat menjadi inspirasi masyarakat pembaca. Salah satu bentuk ilustrasi cerita rakyat yang akan dirancang dengan menggunakan karakter bentuk wayang Papua.

Berdasarkan survey yang dilakukan melalui angket yang diberikan kepada 85 (lima puluh) orang Papua termasuk narasumber lain yang ada di Yogyakarta, mereka sebagian besar menempuh pendidikan di APMD, UST, PGRI, UGM Yogyakarta. Menyatakan bahwa terdapat 93\% responden setuju bahwa cerita rakyat suku Malind dibuat menjadi sebuah buku. Mengacu pada data kuantitatif yang diperoleh dari hasil penyebaran angket dan hasil survey melalui wawancara dengan tokoh-tokoh masyarakat Papua, maka rumusan masalahnya adalah bagaimana merancang cerita rakyat suku Malind ke dalam bentuk buku dengan ilustrasi wayang Papua. Media wayang dihadirkan untuk mengenalkan salah satu hasil budaya Jawa kepada anak - anak. Ilustrasi wayang Papua merupakan perpaduan antara produk budaya Jawa dan Papua. Hal ini sebagai penggalian gagasan/ide yang dapat mengajarkan kepada anak-anak bahwa kreativitas dapat bersumber dari mana saja, dan hasilnya bisa dipadukan menjadikan suatu hal yang baru. Penggabungan bentuk karakter ini diharapkan dapat menginspirasi anak-anak dalam berfikir kreatif dalam berkarya seni dan bisa diaplikasikan ke dalam aspek kehidupan lainnya, sehingga mereka dapat menciptakan hal yang baru, untuk memecahkan sebuah masalah.

Dalam menyampaikan isi dan pesan dari sebuah cerita, akan dihadirkan sebuah karakter yang unik, khas dan spesifik yaitu berupa ilustrasi wayang Papua. Ilustrasi akan berfungsi untuk memperjelas isi cerita tersebut. Fungsi utama ilustrasi adalah untuk menghias dan mendukung guna membantu atau memperjelas suatu objek, dalam hal ini adalah cerita rakyat suku Malind. Umumnya ilustrasi berupa gambar, karena akan lebih mudah untuk dipahami sifat pembacaannya dari pada tulisan. Meskipun demikian tulisan bisa difungsikan sebagai ilustrasi dalam bentuk gambar (tipografi), dalam hal ini 'kata' menjadi unsur verbal yang divisualkan (Koskow, 2013:128).

Perancangan ilustrasi wayang ini terjadi sebagai hasil modifikasi sesuatu yang sudah ada menjadi konsep yang baru, menghubung - kaitkan segala sesuatu yang tadinya tak terhubung. Marianto (2017:1), dengan pengertian lain terdapat dua konsep lama yang dikombinasikan menjadi suatu konsep baru. (Semiawan dalam Iswantara

2017:7) konsep lama disini adalah wayang Jawa yang dikombinasikan dengan ornamen Papua.

\section{METODE}

Perancangan ini menggunakan metode design thinking di dalam metode tersebut menggunakan tahapan membuat karya, langkahlangkah tersebut memiliki pembahasan sebuah karya, tahapan dan langkah memiliki pembahasan yang berbeda. Namun sesuai dengan perancangan sebuah karya dari awal hingga final.

Dari pembahasan di atas dapat disimpulkan bahwa langkah yang digunakan menggunakan emphatize, define, ideate, prototype, testing. Tahapan ini selalu berkaitan dari awal hingga akhir untuk mendapatkan latar belakang masalah, ide, cara penyelesaian, dan mengetahui jawaban yang tepat dari latar belakang masalah.

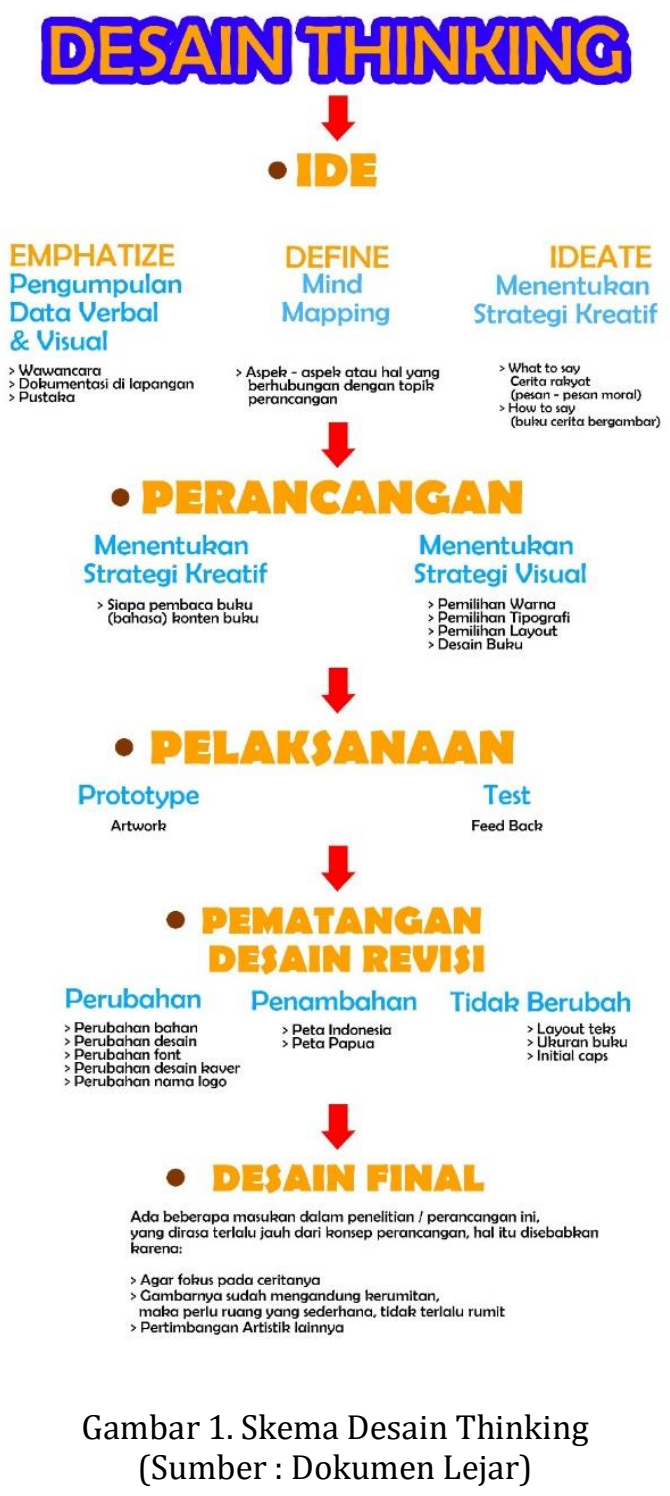




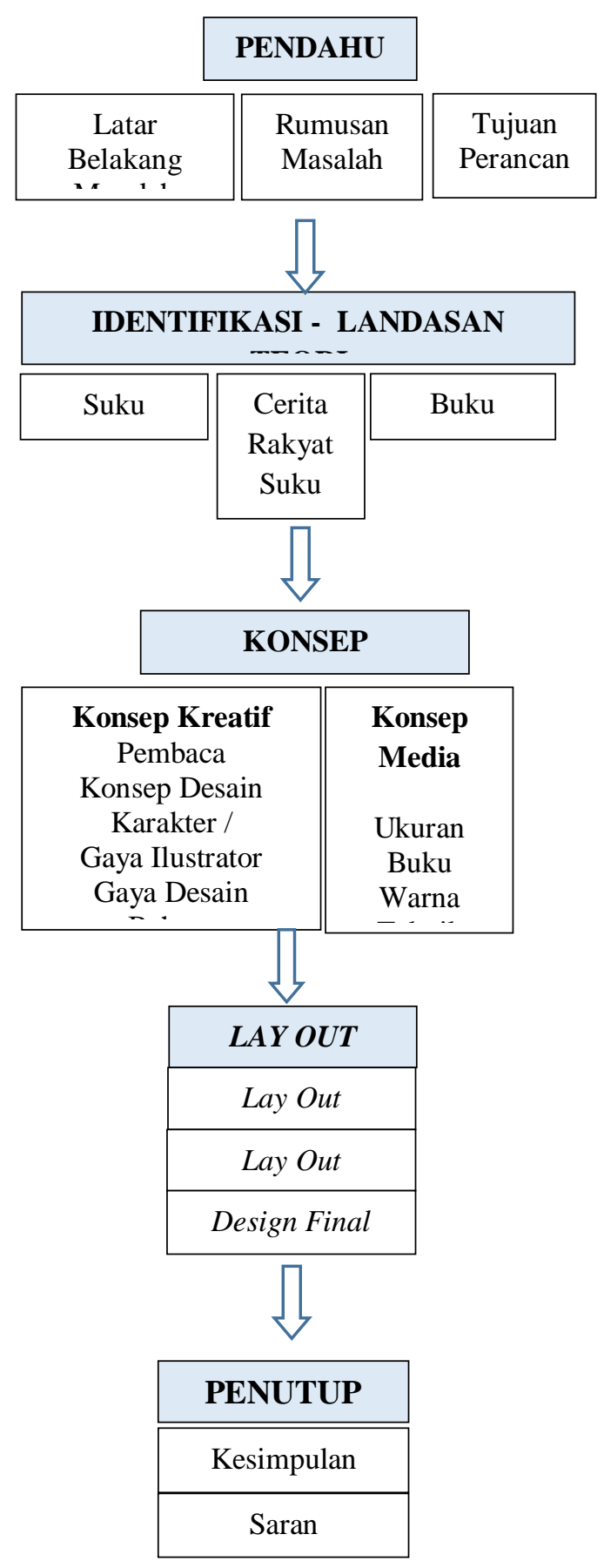

Gambar 2. Sistematika Perancangan

(Sumber: Dokumen Lejar)

Sistematika metode perancangan ilustrasi buku cerita rakyat suku Malind ini meliputi:

1. Pengamatan atau Observasi

a. Mengkaji melalui buku, jurnal dan mencari informasi melalui internet.

b. Hasil wawancara langsung dengan masyarakat Papua, yang berdomisili di Yogyakarta, yang dapat dianggap sebagai narasumber tentang cerita rakyat suku Malind.

2. Pengumpulan Data a. Mengumpulkan data tentang hasil budaya suku Malind di Merauke melalui media cetak dan digital/internet.

b. Wawancara dengan narasumber masyarakat Papua antara lain Penias Hukubun, Bendy, Galio Maniani, dan Ferry Gamgenora.

c. Penyebaran kuesioner yang ditujukan kepada masyarakat Papua dan narasumber lainnya, sebanyak 85 eksemplar. Hal ini digunakan sebagai data kuantitatif, untuk memperkuat data tentang pentingnya cerita rakyat suku Malind menjadi sebuah buku.

3. Identifikasi Data

Setelah semua data terkumpul dan dilakukan pengelompokan berdasarkan kategori, maka selanjutnya dilakukan analisis data dengan menggunakan metode Design Thinking Process. Secara singkat dapat dijelaskan sebagai berikut:

a. Tahap Empathize

Empati sangat penting untuk proses desain yang berpusat pada manusia, artinya penting untuk memahami kebutuhan pengguna, sehingga diperlukan data yang lengkap dengan memahami pengalaman, emosi, dan situasi si pengguna. Untuk itu perlu melakukan wawancara, observasi kehidupan pengguna, dan cara lainnya.

b. Tahap Define

Setelah mendapatkan data yang lengkap pada tahap empati, selanjutnya mendefinisikan masalah sebagai pernyataan masalah berdasarkan kebutuhan pengguna. Selanjutnya, melakukan eksplorasi ide, yang digunakan sebagai produk perancangan yang akan dibuat.

c. Tahap Ideate

Desainer setelah mendapatkan ide, tahap berikutnya adalah membuat alternatif desain untuk mendapatkan solusi terbaik dengan melalui analisis dan sintesis.

d. Tahap Prototype

Solusi terbaik yang telah dipilih pada tahap ideate, selanjutnya perlu dibuat prototipe dalam hal ini adalah ilustrasi karakter wayang Papua, yang akan diterapkan dalam membahasakan cerita rakyat suku Malind dalam bentuk ilustrasi buku.

e. Tahap Test

Berdasarkan produk yang telah dihasilkan yaitu berupa ilustrasi buku cerita rakyat suku Malind, selanjutnya diujicobakan pada pengguna. Pengguna akan memberikan kritik dan saran untuk perbaikan produk yang ada.

f. Sintesis

Berdasarkan proses analisis dilakukan proses sintesis. Hasil dari sintesis ini dijadikan acuan visual dalam merancang buku ilustrasi, yaitu dengan melakukan 


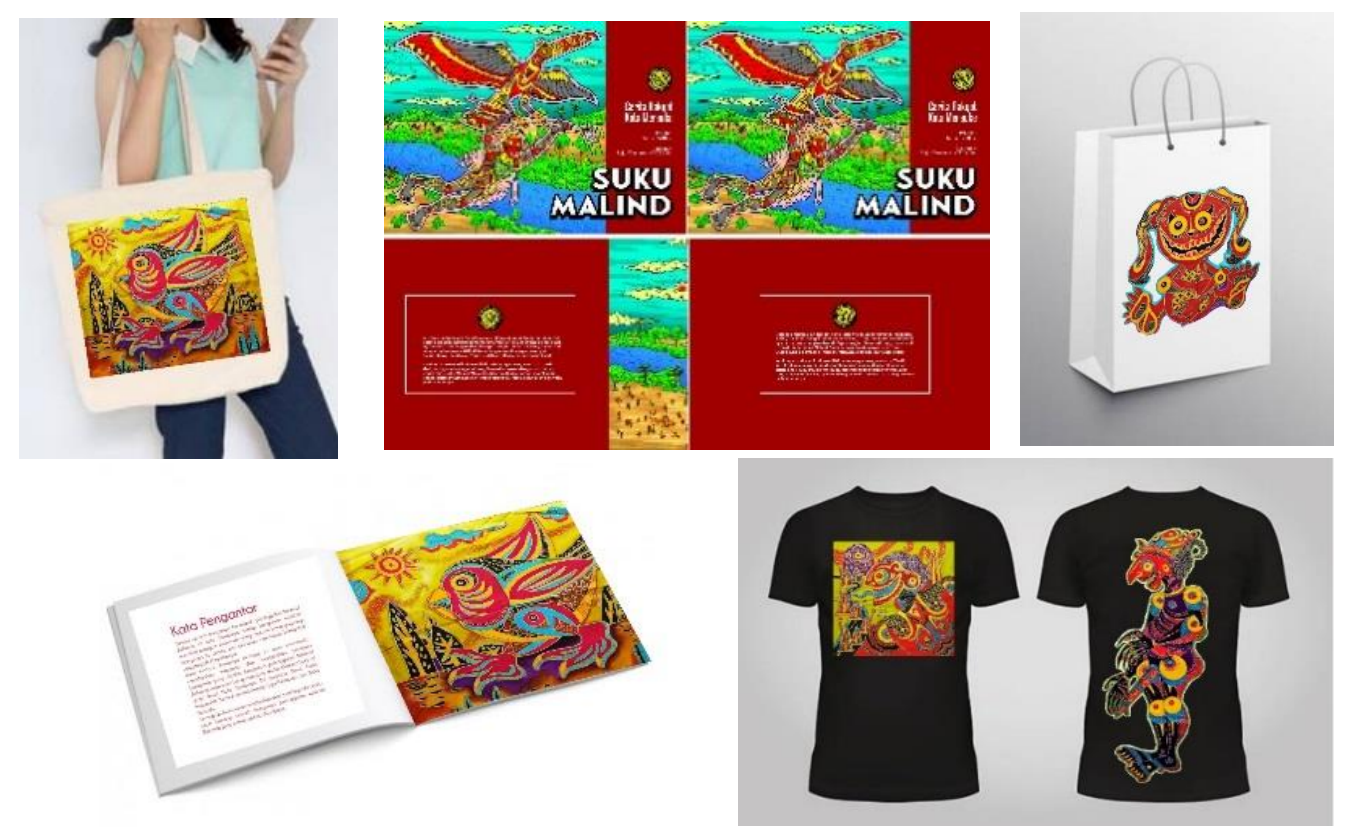

Gambar 3. Aplikasi Karya

(Sumber : Peneliti)

perencanaan kreatif yang meliputi tujuan, strategi, program, dan anggaran.

g. Aplikasi

Bentuk perancangan ilustrasi buku Cerita Rakyat Suku Malind dengan menggunakan ilustrasi karakter Wayang Papua, dalam upaya pelestarian dan pengenalan budaya Suku Malind Kabupaten Merauke pada masyarakat.

\section{PEMBAHASAN}

Berikut ini adalah salah satu dari karya ilustrasi cerita rakyat yang berjudul "Asal Mula Terjadinya Ikan Bulanak". Perjalanan panjang yang dilakukan oleh ikan-ikan bulanak dengan induknya yang sangat setia dengan seorang rajanya darimanakah datangnya ikan-ikan ini? Baiklah kita hendak mengetahuinya, mereka berasal dari arah timur Kabupaten Merauke.

Ada seorang penangkap ikan yang berusaha dengan cara magis untuk menangkap ikan-ikan itu, tetapi sayangnya ia tidak dapat mendekati induk bulanak itu. Kemudian dia jatuh dan terguling ke dalam sungai, dengan tenaganya ia bangkit, dan pada akhirnya ia berhasil menangkap ikan tersebut dan dibawa ke sebuah sungai kecil bernama Yowib di Kampung Dufmirah Distrik Okaba.

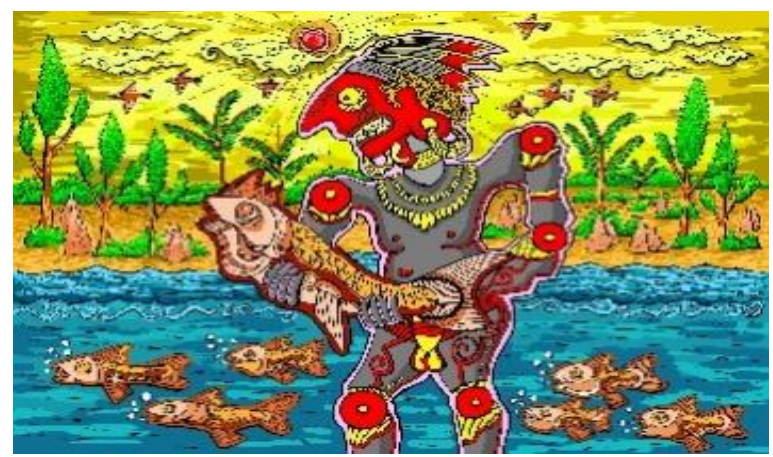

Gambar 4. Penangkap Ikan

(Sumber : peneliti)

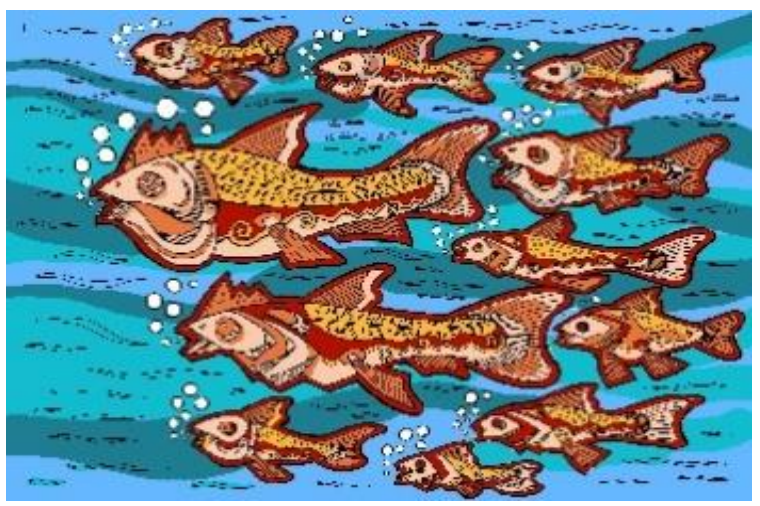

Gambar 5. Kawanan Ikan

(Sumber : peneliti) 


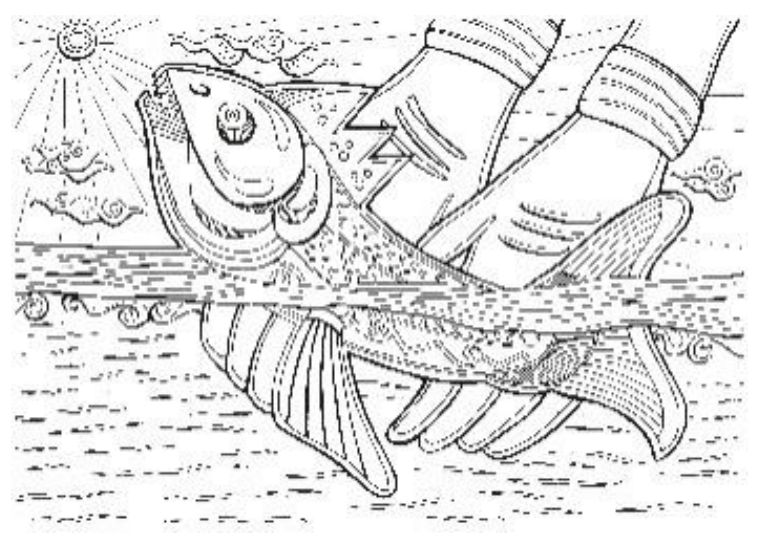

Gambar 6. Ilustrasi Asal Mula Ikan Bulanak (Sumber : Peneliti)

Gambar ilustrasi yang ada di sini menggambarkan asal mula terjadinya ikan bulanak yang digambarkan secara dekoratif dengan warna yang bewarna-warni sehingga diharapkan anakanak dapat menumbuhkan minat baca. Manfaatnya dari sejak dini mereka sudah mengenal budaya Malind, dengan media buku dan karakter yang baru wayang Papua, yang menokohkan cerita rakyat Malind.

\section{KESIMPULAN}

Penyampaian buku cerita rakyat suku Malind kepada anak - anak usia 10 - 12 tahun, menggunakan media buku cetak, sangatlah mendukung. Karena tidak membutuhkan listrik, saat buku tersebut tersebar di daerah yang kurang listrik. Membaca buku cetak, akan membuat mereka lebih konsentrasi dalam membaca, dari pada menggunakan gadget, selain itu mereka dapat mengenal kertas dan terlatih dalam merawat buku. Pengenalan budaya Malind, sejak usia dini sangat diperlukan. Sehingga saat mereka dewasa, mereka dapat mengingat, mengerti dan paham dengan moral dan kebudayaan mereka.

\section{DAFTAR PUSTAKA}

Ambrose, Gavin., dan Paul Harris. 2010. Design Thikning, AVA Publishing SA, Switzerland.

Budiman, Kris. 2011. Semiotika Visual, Konsep, Isu, dan Problem Ikonisitas. Yogyakarta: Jallasutra.

Dirgantara, Satrya. 2015. Perancangan Buku Ilustrasi Surabaya Heritage. Tesis. Yogyakarta: Institut Seni Indonesia.

Dewayani, Sofie. 2017. Menghidupkan Literasi di Ruang Kelas. Yogyakarta: Kanisius.

Gamgenora, Fr Ferry, S.Psi. 2010. Apa Sebab Anak Bisa Nakal. Yogyakarta: Bajawa Press.
Gamgenora, Fr Ferry, S.Psi. 2014. Psikologi Cinta Mengenal Cinta Palsu. Yogyakarta: Bajawa Press.

Gamgenora, Fr Ferry, S.Psi. 2014. Psikologi Belajar Apa Sebab Habis Belajar Lalu Lupa. Yogyakarta: Bajawa Press.

Hukubun, Daniartana Lejar. 2015. Perancangan Ilustrasi dengan Karakter Bercorak dan Berteknik Batik untuk Novel Republik Rimba Karya Ryan Sugiarto. Yogyakarta: Mandiri.

Ihromi, T.0. 1980. Pokok-pokok Antropologi Budaya. Jakarta: Penerbit PT Gramedia.

Iswantara Nur Dr. M. Hum. 2017. Kreativitas Sejarah, Teori, dan Perkembangan. Yogyakarta: Gigih Pustaka Mandiri.

Iyan, Wb. 2007. Anatomi Buku. Bandung: Kolbu.

Istijanto. 2005. Riset Sumber Daya Manusia. Jakarta: PT. Gramedia Pustaka.

Kadiasti, Ristia. 2015. Perancangan Buku Ilustrasi Sejarah Stasiun Samarang. Tesis. Yogyakarta: Institut Seni Indonesia Yogyakarta.

Kompas, Laporan Jurnalistik. 2009. Ekspedisi Tanah Papua. Jakarta: Kompas.

Koskow. 2009. Merupa Buku. Yogyakarta: Lkis.

Kamus Besar Bahasa Indonesia. 2001. Jakarta: Balai Pustaka.

Marianto, Dwi M. 2017. Art \& Life Force in a Quantum Perspective. Yogyakarta: Scritto,

Marahimin, Ismail. Hadits, Fawzia Aswin. 2012. Kreatif Menulis Cerita Anak. Bandung: Nuansa.

Mangunwijaya, Pr. YB. 1998. Gereja Diaspora. Yogyakarta: Kanisius.

Maharsi, Indira, M.Sn. 2016. Ilustrasi. Yogyakarta: ISI.

Peday, Ayub; Kanggam, Willibrordus, Mahuze. M Yoseph; Ronggo D. Alexius. 2013. Kumpulan Cerita Rakyat Daerah Malind. Merauke: Dinas Kebudayaan dan Pariwisata Kabupaten Merauke.

Samkakai, Frumensius Obe. Hollenger, Daud. Ndiken, Isayas Yanggel. 2013. Tanah Malind suatu Pendekatan Pemetaan Budaya Suku Bangsa. Merauke: Dinas Kebudayaan dan Pariwisata Kabupaten.

Sarumpaet, Toha. K. Riris. 2016. Pedoman Penelitian Sastra Anak. Yogyakarta: Obor.

Tinarbuko, Sumbo. 2016. DEKAVE Desain Komunikasi Visual Penanda Zaman. Yogyakarta: Caps.

Tinarbuko, Sumbo. 2009. Semiotika Komunikasi Visual. Yogyakarta: Caps.

Titik. WS., Sarumpaet Toha, Riris K. Basino P.l, Titis, Layun Rampan, Sumardi, Korrie. Marahimin, Ismail. Hadits, Fawzia Aswin. 2012. Kreatif Menulis Cerita Anak. Bandung: Nuansa. 